\title{
Control of NMDA Receptor Activation by a Glycine Transporter Co-Expressed in Xenopus Oocytes
}

\author{
Stéphane Supplisson and Claude Bergman \\ Laboratoire de Neurobiologie, Centre National de la Recherche Scientifique, Unité de Recherche Associée 1857, Ecole \\ Normale Supérieure, 75005 Paris, France
}

\begin{abstract}
We present evidence that membrane transporters can control the membrane receptor's agonist concentration in restricted extracellular spaces of a biological model. The model is constructed by co-expressing glycine/Na/Cl cotransporters (GLYT1b) and NMDA receptors (NMDARs) (composed of the subunits NR1 and NR2A or NR2B) in Xenopus oocytes. We use the high-affinity glycine site of the NMDARs as a sensor of the actual juxtamembrane glycine concentration. We show that glycine uptake by GLYT1b dramatically reduces NMDAR currents by reducing the glycine concentration in extracellular spaces in which diffusion is restricted. This effect appears only in oocytes in which GLYT1b and NMDAR are co-expressed. It is $\mathrm{Na}^{+}$- and voltage-dependent, and is abolished when $\mathrm{Na}^{+}$is replaced by $\mathrm{Li}^{+}$and when glycine is replaced by
\end{abstract}

D-serine (a coagonist of the NMDAR that is not transported by GLYT1b). These results demonstrate the ability of the GLYT transporter to reduce glycine concentration at the level of NMDARs in restricted diffusion spaces. This observation could account for a prevalent role of membrane transporters in the modulation of synapse transmission in the CNS. From a more general point of view, our results draw attention to possible significant discrepancies between local concentrations at the level of substrate targets in biological membranes and their concentration in the bulk solution when membrane transporters are present.

Key words: glutamate receptor; NMDA; coagonist; D-serine; sarcosine; synaptic cleft
In most studies, membrane cotransporters have been regarded as pumps responsible for accumulating organic constituents into cells or regulating the cytosolic concentration of electrolytes. However, their physiological function can be also regarded as a mean to control substrate concentration in the extracellular compartment. In neurons and glial cells, specific transporters actively take up neurotransmitters or their metabolites, thus contributing to the recycling of messengers and the termination of the synaptic transmission (Barbour et al., 1994; Tong and Jahr, 1994).

Accumulation of substrate into cells (Guastella et al., 1992; Smith et al., 1992; Kim et al., 1994) or measurements of the membrane current generated during transport cycles (Brew and Attwell, 1987; Mager et al., 1993) have been commonly used as an index of the transporter activity. Only a few studies have considered the physiological relevance of substrate concentration changes arising in the extracellular space from transporter activity (see Barry and Diamond, 1984; Nicholson, 1995). This function of transporters, however, should be regarded as particularly important for the control of the glycine concentration in excitatory glutamatergic synapses. As glycine is recognized as a necessary coagonist of glutamate at the level of the NMDA receptor (NMDAR) (Johnson and Ascher, 1987; Kleckner and Dingledine, 1988; Benveniste et al., 1990), the physi-

\footnotetext{
Received Jan. 17, 1997; revised March 27, 1997; accepted March 31, 1997.

This work was supported by the Centre National de la Recherche Scientifique and a grant from the European Community (contract BMH4CT950571). We thank Philippe Ascher for his support, advice, and help in preparing this manuscript; Boris Barbour for critical review; Stéphane Dieudonné for discussion; Albert Berger, Jonathan Bradley, Jacsue Kehoe, Jürgen Kupper, Pierre Paoletti, Michel Roux, and Ralf Schneggenburger for suggestions and comments on this manuscript; Jacques Neyton for the expression of NMDAR; Karl Hager and Ernest M. Wright for the original expression of GLYT1b in oocytes; Bernard Lacaisse for building the oocyte chamber; and Bernard Martin for the motorized valve controller.

Correspondence should be addressed to Dr. Stéphane Supplisson, Laboratoire de Neurobiologie, Centre National de la Recherche Scientifique, Unité de Recherche Associée 1857, Ecole Normale Supérieure, 46 rue d'Ulm, 75005 Paris, France Copyright (C) 1997 Society for Neuroscience $0270-6474 / 97 / 174580-11 \$ 05.00 / 0$
}

ological relevance of possible variations in glycine concentration has remained elusive (Thomson, 1990; Kemp and Leeson, 1993; Wilcox et al., 1996), primarily because the actual concentration of glycine inside the synaptic clefts of glutamatergic neurons remains unknown. This uncertainty has led to the assumption that the glycine concentration in the synaptic cleft is close to the values $(1-10 \mu \mathrm{M})$ measured in the CSF (Westergren et al., 1994), which corresponds to a saturating level for the glycine site of most NMDARs. In contrast, based on the thermodynamics of the transporter, which predicts a limiting external glycine concentration in the $100 \mathrm{~nm}$ range, it has been suggested that an active uptake of glycine by transporters might be sufficient to reduce below saturation the glycine concentration in the synaptic cleft (Ascher, 1990; Attwell and Bouvier, 1992; Attwell et al., 1993), thereby allowing the variations in the local glycine concentration to become a signal acting on NMDARs. This hypothesis has two major kinetic limitations. First, it supposes that glycine uptake is efficient when the glycine concentration is one to two orders of magnitude below the apparent glycine affinity. Secondly, it implies that the uptake can overcome the passive diffusion flux from the CSF into the restricted extracellular space of the CNS.

In the present paper, we describe the results of an experimental analysis performed on a biological model in which membrane transporters (the glycine transporter GLYT1b) control the responses of the NMDARs. The model is constructed by coexpressing both the carrier and the receptor in Xenopus oocytes. We show that because of unstirred layers near the membrane, the extracellular glycine concentration in the juxtamembrane space $\left([G l y]_{\mathrm{m}}\right)$ can be reduced dramatically by specific transporters well below the bath concentration $\left([G l y]_{\mathrm{b}}\right)$.

\section{MATERIALS AND METHODS}

Heterologous expression of GLYT1b and NR1-NR2A NMDA subunits in Xenopus oocytes. Among the glycine transporters cloned from the brain and spinal cord [GLYT1a (Guastella et al., 1992), 1b (Smith et al., 1992); 


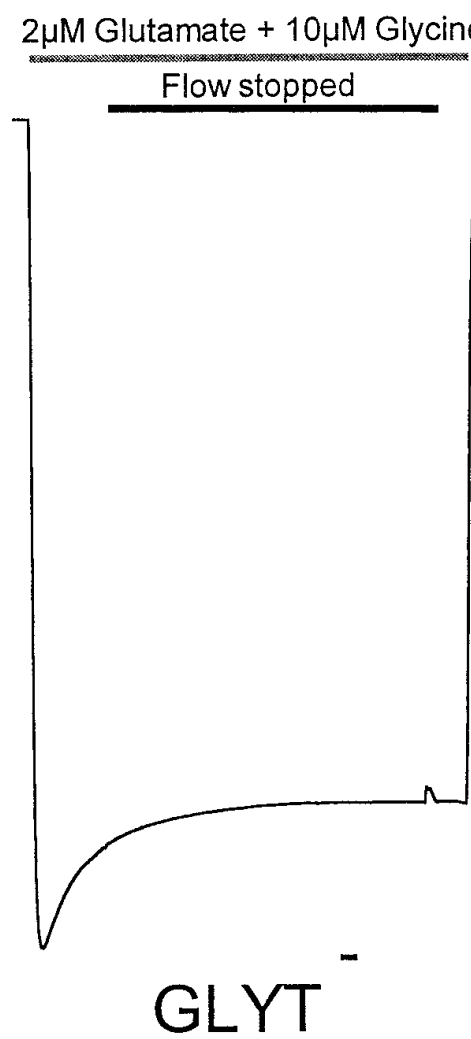

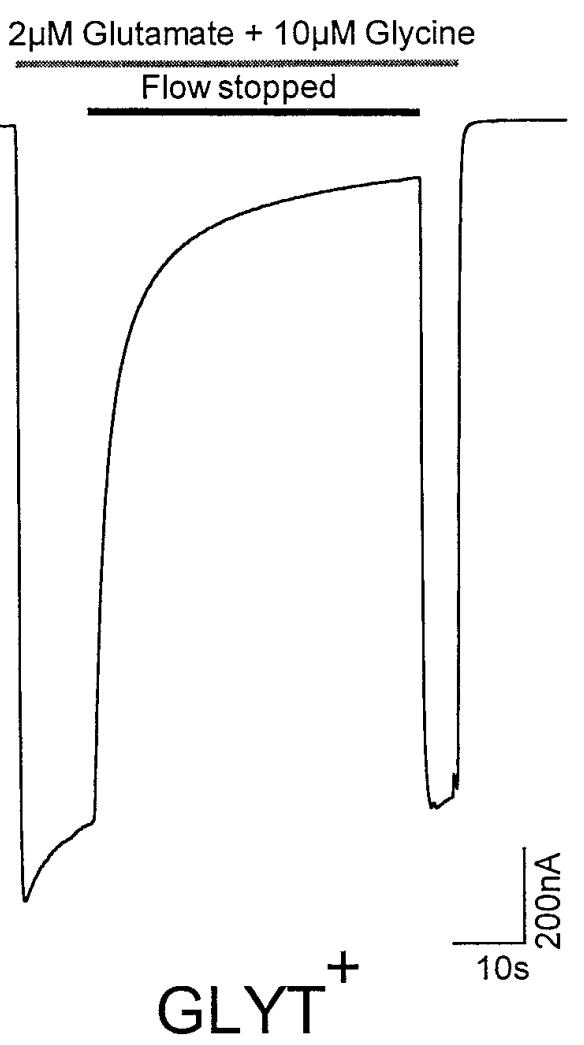

Figure 1. Inhibition of NMDAR activity by glycine uptake in $\mathrm{GLYT}^{+}$oocytes. NMDARs were activated continuously (gray bar) by a solution containing $2 \mu \mathrm{M}$ glutamate and $10 \mu \mathrm{M}$ glycine. In $\mathrm{GLYT}^{-}$ oocyte (left), interruption of the flow of solution (solid bar) had no effect on the NMDAR current. In contrast, when the flow of the solution was stopped in $\mathrm{GLYT}^{+}$oocyte (right), the NMDAR current decreased by $93 \%$, after a double exponential time course. Restarting the flow restored the full amplitude of the NMDAR current. 1c (Kim et al., 1994), and GLYT2 (Liu et al., 1993)], GLYT1b was selected because it has been shown to be co-localized with NMDARs in neural tissues (Smith et al., 1992; Adams et al., 1995; Luque et al., 1995; Zafra et al., 1995). The NR1 and NR2A subunits have been chosen for most experiments, because the relatively low glycine affinity (Kutsuwada et al., 1992) of the receptor prevents its saturation in the 1-10 $\mu \mathrm{M}$ glycine range. Complementary experiments were performed using the NR2B subunit to analyze the modulation of NMDAR at low glycine concentration.

Defolliculated oocytes were isolated from Xenopus laevis ovaries after $1 \mathrm{hr}$ of shaking incubation in OR-2 $\mathrm{Ca}^{2+}$-free medium containing 2 $\mathrm{mg} / \mathrm{ml}$ of collagenase type II. The vitelline envelope was not removed, because the oocyte became too fragile to withstand rapid superfusion (Costa et al., 1994). The NMDAR subunits NR1-1a [pN60, the gift of S. Nakanishi (Moriyoshi et al., 1991)]), NR2A and NR2B [gifts of P. Seeburg (Monyer et al., 1992)], and GLYT1b [the gift of K. Smith, Synaptic Corporation (Smith et al., 1992)] were subcloned in a pRc-CMV vector (Invitrogen, San Diego, CA) containing the 5'-UTR of the alfalfa mosaic virus (Mager et al., 1993) and a poly-A tail. Most of the $5^{\prime}-$ and 3'-UTR of the NR1, NR2A, and NR2B subunits were deleted (Kupper et al., 1996). Expression of the NR1-NR2A or NR1-NR2B subunits of NMDAR was achieved by nuclear injection of cDNA coding for each subunit (Kupper et al., 1996) or by mRNA injection in combination with GLYT1b. Oocytes were kept at $19^{\circ} \mathrm{C}$ in individual vials containing $200 \mu \mathrm{l}$ of Barth's solution supplemented with $50 \mu \mathrm{g} / \mathrm{ml}$ gentamycin and $200 \mu \mathrm{M}$ DL-2-amino-5-phosphonopentanoic acid. Experiments were performed at room temperature, 2-3 d after the NMDAR mRNA injection.

Experimental procedures. The oocytes were introduced into a tubular superfusion chamber that allowed a fast and laminar flow around the oocyte (at saturating glutamate and glycine concentrations, the typical $10-90 \%$ rise time for the NMDAR response was $150 \mathrm{msec}$ ). The flow of solution was interrupted manually by closing two coupled valves at either end of the oocyte chamber. Change of solution was achieved by means of a motorized valve. To avoid contamination of the NMDAR current by the endogenous $\mathrm{Ca}^{2+}$-activated $\mathrm{Cl}^{-}$conductance (Leonard and Kelso, 1990), the extracellular recording solution was $\mathrm{Ca}^{2+}$-free and contained (in mM): $100 \mathrm{NaCl}, 0.3 \mathrm{BaCl}_{2}, 5$ HEPES, pH 7.2 adjusted with KOH.

Data acquisition. Whole-cell currents were recorded under two electrode voltage-clamp at a holding potential of $-70 \mathrm{mV}$ using a Warner OC-725A amplifier. Both current and voltage microelectrodes were filled with $3 \mathrm{M} \mathrm{KCl}$ and had a tip resistances of $<2 \mathrm{M} \Omega$. The two electrodes impaled the oocyte in the equatorial region at an angle of $180^{\circ}$ relative to each other. A reference $\mathrm{Ag} / \mathrm{AgCl}$ pellet was placed close to the oocyte. The currents were filtered at $40 \mathrm{~Hz}$ and digitized at $100 \mathrm{~Hz}$. The leakage currents were subtracted on display.

Estimation of the $[\mathrm{Gly}]_{m}$. In $\mathrm{GLYT}^{+}$oocytes, the $[G l y]_{\mathrm{m}}$ sensed by the NMDARs was calculated by reversing the Hill equation:

$$
[G l y]_{\mathrm{m}}=\frac{\mathrm{EC}_{50}}{\sqrt[n]{\frac{I_{\mathrm{max}}}{I}-1}}
$$

where $I$ is the NMDA evoked current, $I_{\max }$ is the maximal current at saturating glycine concentration and where Glycine $\mathrm{EC}_{50}$ and the Hill coefficient $(n)$ refer to the mean values measured in $\mathrm{GLYT}^{-}$oocytes.

In stopped-flow condition, a similar procedure was followed using experiments repeated at a different glycine concentration. First, the initial glycine concentration (before the stopped-flow condition) was estimated as described above, then $[G l y]_{\mathrm{m}}$ was calculated as a function of time using the NMDAR current ratio $I_{\mathrm{t}=0} / I_{\mathrm{t}}$.

\section{RESULTS}

\section{Reduction of NMDA currents in GLYT $^{+}$oocytes under stopped-flow condition}

In the following experiments, activation of the NMDARs was routinely obtained by prolonged $(\sim 70 \mathrm{sec})$ exposures of the oocytes to the control medium containing glutamate and glycine at constant concentrations. The membrane was voltage-clamped to $-70 \mathrm{mV}$, and on the sudden arrival of the test solution, it generated a large (several microamperes) inward current (downward in the figures) carried by $\mathrm{Na}^{+}$ions (see Materials and Methods). In control oocytes expressing only NR1-NR2A NMDARs (GLYT ${ }^{-}$ oocytes), the current remained stable irrespective of whether the solution superfusing the oocyte was flowing (Fig. 1, left). In contrast, in oocytes co-expressing NMDAR and GLYT1b $\left(\mathrm{GLYT}^{+}\right.$ oocytes), abruptly stopping the flow of the superfusate resulted in a marked decrease of the NMDA current, as shown on the right 


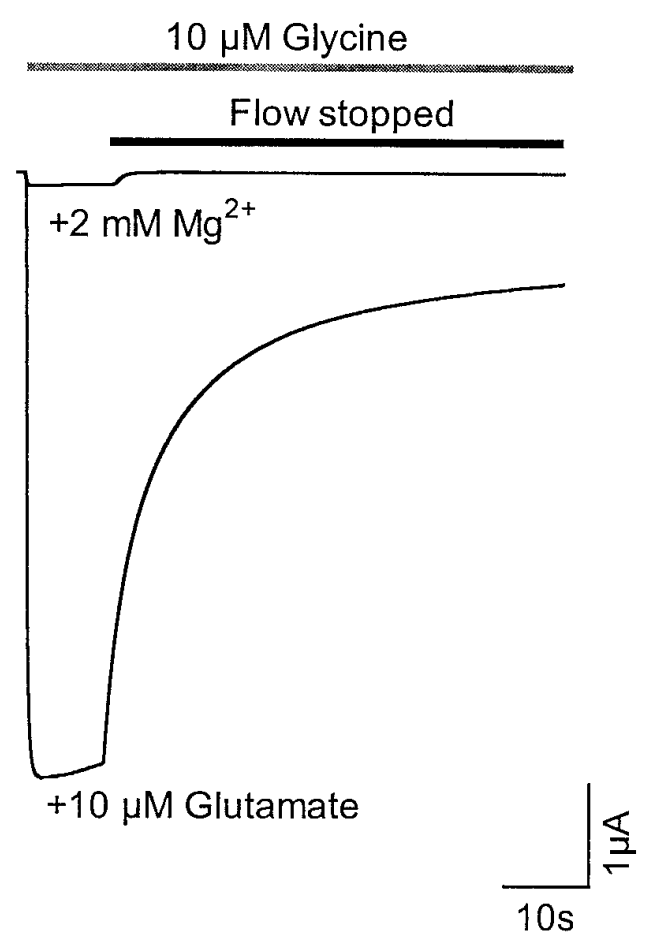

Figure 2. The contribution of the uptake current is negligible. The contribution of the glycine uptake current to the total current evoked by the application of glycine and glutamate was estimated to be $<3 \%$ of the total current by comparing the current activated by $10 \mu \mathrm{M}$ glycine $+10 \mu \mathrm{M}$ glutamate with $1-10 \mu \mathrm{M}$ glycine $+2 \mathrm{mM} \mathrm{MgCl}_{2}$.

in Figure 1 (mean inhibition $=80 \pm 13 \%(\mathrm{SD}), n=51$, for $[G l y]_{\mathrm{b}}$ $=10 \mu \mathrm{M})$. The decay of the current followed an approximately biexponential time course $\left(\tau_{\text {fast }}=1.5 \mathrm{sec}\right.$ and $\left.\tau_{\text {slow }}=11.4 \mathrm{sec}\right)$, with the fastest component being the largest (65\%). Reinstating the flow restored the full amplitude of the current. This phenomenon will be called as "stopped-flow" inhibition of NMDARs.

The contribution of the uptake current to the total current evoked by glycine in GLYT $^{+}$oocytes was evaluated by applying glycine alone while blocking NMDARs with $2 \mathrm{~mm}$ extracellular $\mathrm{Mg}^{2+}$. As shown in Figure 2 (top trace), the residual current was $<3 \%$ of the total current evoked in the presence of glutamate (bottom trace) and disappeared when the flow was stopped. Similar results were obtained using $100 \mu \mathrm{M}$ D-APV (see Fig. 9C).

\section{The inhibition of NMDAR results from the local depletion of glycine by the transporter}

We interpret the reduction of NMDAR current on stopping the flow as reflecting the depletion of glycine by the transporter in the vicinity of the NMDARs. Additional evidence supports this view as follows.

Replacing extracellular $\mathrm{Na}^{+}$by $\mathrm{Li}^{+}$(Fig. 3) prevents stoppedflow inhibition of NMDAR. This is explained by the fact that $\mathrm{Li}^{+}$ can replace $\mathrm{Na}^{+}$in the NMDA channel with a lower permeability (Tsuzuki et al., 1994) but not at the level of the glycine transporter (Guastella et al., 1992; Smith et al., 1993; Kim et al., 1994).

Increasing $[G l y]_{\mathrm{b}}$ slows the development of the stopped-flow inhibition and reduces its extent (Fig. 4); with $[G l y]_{\mathrm{b}} \geq 100 \mu \mathrm{M}$, stopping the flow no longer produces an inhibition. This is expected for a saturable uptake process operating in the face of a nonsaturable diffusion process.

Using D-serine in place of glycine does not induce stopped-flow inhibition (Fig. 5). This arises from the fact that D-serine is an agonist of NMDAR (Thomson, 1990) (see also Fig. 8B) but is not transported by GLYT1b. Figure 6 confirms this interpretation, showing that the transport current recorded in an oocyte expressing only GLT1b is almost nil in the presence of D-serine $(0.04 \pm$ $0.03 \%$ of the saturating glycine uptake current; $n=6$ ). Figure 6 shows also that sarcosine is transported by GLYT1b but with a lower $I_{\max }(76 \pm 4 \% ; n=10)$ of the saturating glycine uptake current), thereby explaining that the addition of $300 \mu \mathrm{M}$ sarcosine to $10 \mu \mathrm{M}$ glycine prevents the stopped-flow inhibition (data not shown; $n=3$ ) of the NMDAR current by saturating the transporters.

Hyperpolarizing the membrane increases the inward NMDA current much less than expected from the linear current-voltage relationship usually generated in the absence of external $\mathrm{Mg}^{2+}$ ions. This occurs because hyperpolarization stimulates glycine uptake, thereby leading to a reduction of the $[G l y]_{\mathrm{m}}$. Figure 7 illustrates the effects of voltage steps on the NMDAR current in the presence of glycine or its nontransportable analog D-serine. In the presence of either coagonist, stopping the flow at a holding potential of $+10 \mathrm{mV}$ induces little inhibition of the (outward) NMDA current, because uptake is already strongly inhibited at this potential. At hyperpolarization to $-30 \mathrm{mV}$, the increased driving force leads to an instantaneous increase of the current amplitude, which declines slowly in the presence of glycine, reflecting a decrease of $[G l y]_{\mathrm{m}}$. Additional hyperpolarizing steps lead to longer increases of the NMDA current in the presence of D-serine but with glycine only induced small augmentations. In four experiments, the NMDA current in the presence of $10 \mu \mathrm{M}$ $[G l y]_{\mathrm{b}}$ increases by $3 \pm 0.35 \%(n=4)$ on stepping from -30 to $-90 \mathrm{mV}$. On the other hand, in the presence of D-serine, a much larger increase $(195 \pm 12 \%, n=3)$ is observed for the same voltage steps, a value that is close to the linear variation predicted from NMDA channel properties.

\section{The inhibition of NMDA currents in GLYT ${ }^{+}$oocytes also occurs under fast-flow condition}

The decrease in $[G l y]_{\mathrm{m}}$ occurring during the stopped-flow period can be estimated from the observed NMDAR current reduction on the basis of dose-response relationships between the glycine concentration and the NMDAR current. This requires a knowledge of $[G l y]_{\mathrm{m}}$ at $t=0$ (i.e., under fast-flow condition). At a first attempt, we have assumed $[G l y]_{\mathrm{m}}$ to be equal to $[G l y]_{\mathrm{b}}$ under fast-flow conditions for both $\mathrm{GLYT}^{-}$and $\mathrm{GLYT}^{+}$oocytes. Comparison of the glycine activation curves of NMDARs (Fig. 8A), however, revealed that the $\mathrm{EC}_{50}$ was $2.3 \pm 0.3 \mu \mathrm{M}$ in $\mathrm{GLYT}^{-}$ oocytes (solid circles, $n=14, \mathrm{SD}$ ) and $9 \pm 1.3 \mu \mathrm{M}$ in $\mathrm{GLYT}^{+}$ oocytes (open circles, $n=4$; individual experiments are shown). The Hill coefficient increased from $1.2 \pm 0.3$ to $1.6 \pm 0.13$. In contrast, as shown in Figure $8 B$, the $\mathrm{D}$-serine $\mathrm{EC}_{50}$ is similar in $\mathrm{GLYT}^{-}$(solid diamonds) and $\mathrm{GLYT}^{+}$oocytes (open diamonds). This suggests that at variance with our preliminary interpretation (Supplisson et al., 1994), the glycine transporters can decrease $[G l y]_{\mathrm{m}}$ even under fast-flow conditions, generating a steady-state glycine gradient $\left(\Delta[G l y]=[G l y]_{\mathrm{b}}-[G l y]_{\mathrm{m}}\right)$ between the bath solution and the membrane [possibly across a thin, unstirred layer corresponding to the vitelline envelope (Costa et al., 1994) and/or the microvillous layer (Zampighi et al., 1995)]. The different apparent affinities are observed even at the earliest response time (Fig. $8 C$ ), thus demonstrating that the glycine gradient is established as fast as the change in solution. To calculate the effective $[G l y]_{\mathrm{m}}$ sensed by the NMDARs for each $[G l y]_{\mathrm{b}}$, we used the mean $\mathrm{EC}_{50}$ and Hill coefficient of glycine activation of NMDARs as 
$20 \mu \mathrm{M}$ Glutamate $+20 \mu \mathrm{M}$ Glycine

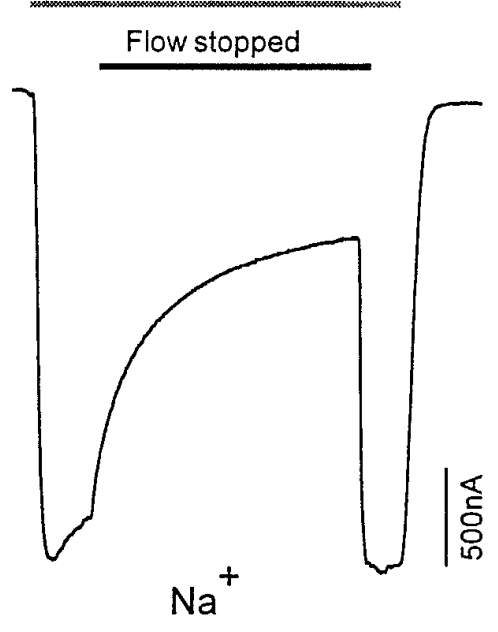

$20 \mu \mathrm{M}$ Glutamate $+20 \mu \mathrm{M}$ Glycine

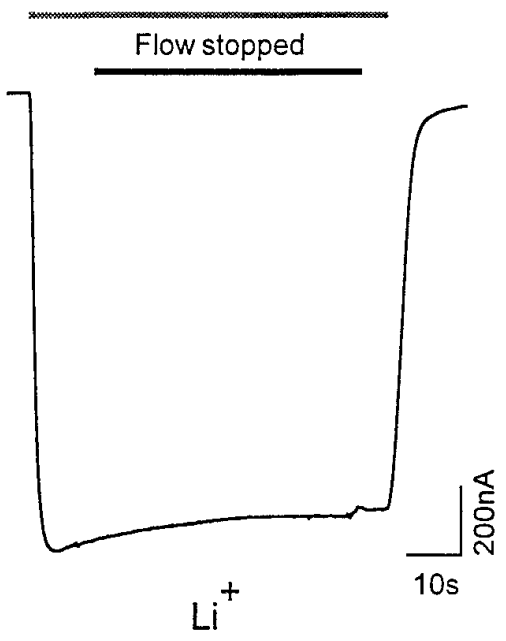

Figure 3. The inhibition of NMDAR by the glycine transporter is $\mathrm{Na}^{+}$-dependent. The stopped-flow inhibition of the NMDAR current is $\mathrm{Na}^{+}$-dependent (left trace), because it is not observed with $\mathrm{Li}^{+}$-Ringer (same oocyte, right trace); note the change in current scale attributable to the reduction by $44 \%$ of the NMDAR current observed in $\mathrm{Li}^{+}$. This decrease in NMDAR current amplitude was expected but somewhat smaller than the predicted $60 \%$ decrease calculated from the reported reduction by $55 \%$ of the single channel current conductance and the shift of reversal potential by $-8 \mathrm{mV}$ for the $\epsilon 2 / \zeta 1 \mathrm{NMDAR}$ subunits expressed in Xenopus oocyte (Tsuzuki et al., 1994). This discrepancy may suggest that the NMDAR current in $\mathrm{Na}^{+}$is already reduced under fast perfusion in $\mathrm{GLYT}^{+}$oocyte.

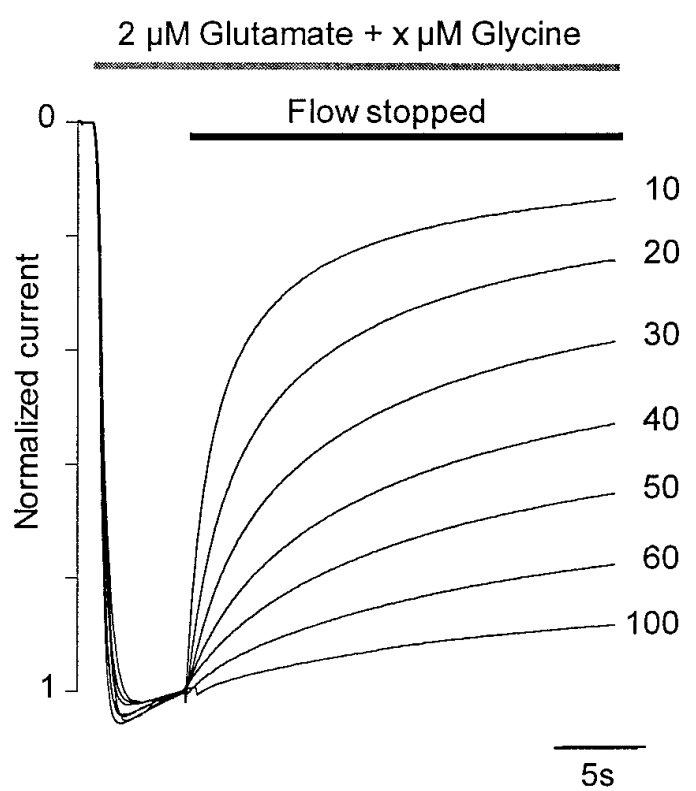

Figure 4. The stopped-flow inhibition of NMDAR in $\mathrm{GLYT}^{+}$oocytes is glycine-dependent. The stopped-flow inhibition of NMDAR decreases in magnitude and slows down with increasing $[G l y]_{b}$; it no longer occurs with $100 \mu \mathrm{M}$ glycine. The current traces were normalized to the value measured before the interruption of the flow.

determined in $\mathrm{GLYT}^{-}$oocytes. Figure $8 D$ shows that for $[G l y]_{\mathrm{b}}$ ranging from 1 to $10 \mu \mathrm{M}$, the $[G l y]_{\mathrm{m}}$ is reduced by four- to sixfold; the mean $[G l y]_{\mathrm{m}}$ values (solid line) were $130 \pm 60 \mathrm{~nm}, 310 \pm 120$ $\mathrm{nM}, 580 \pm 173 \mathrm{nM}, 1.2 \pm 0.5 \mu \mathrm{M}$, and $2.5 \pm 0.8 \mu \mathrm{M}$ for $[G l y]_{\mathrm{b}}=1$, $2,3,6$, and $10 \mu \mathrm{M}$, respectively (SD, $n=4$ ). This method of estimation of $[G l y]_{\mathrm{m}}$ was then applied to the stopped-flow condition. A plot of $[G l y]_{\mathrm{m}}$ as a function of time is shown in a semilog plot in Figure $8 E$. The arrows indicate the $\Delta[\mathrm{Gly}]$ present under fast-flow condition. The final values of $[G l y]_{\mathrm{m}}$ are $70 \pm 26,190 \pm$ 60 , and $530 \pm 120 \mathrm{nM}$ for $[G l y]_{\mathrm{b}}=5,10$, and $20 \mu \mathrm{M}$, respectively.

\section{Relaxation of NMDAR currents induced by voltage} changes in GLYT ${ }^{+}$oocytes under fast-flow condition

To explore further the capacity of glycine transporters to control $[G l y]_{\mathrm{m}}$ under fast-flow superfusion, we performed a set of experiments in which the rate of glycine uptake was altered by abrupt

\section{$10 \mu \mathrm{M}$ Glutamate $+10 \mu \mathrm{M}$ coagonist}

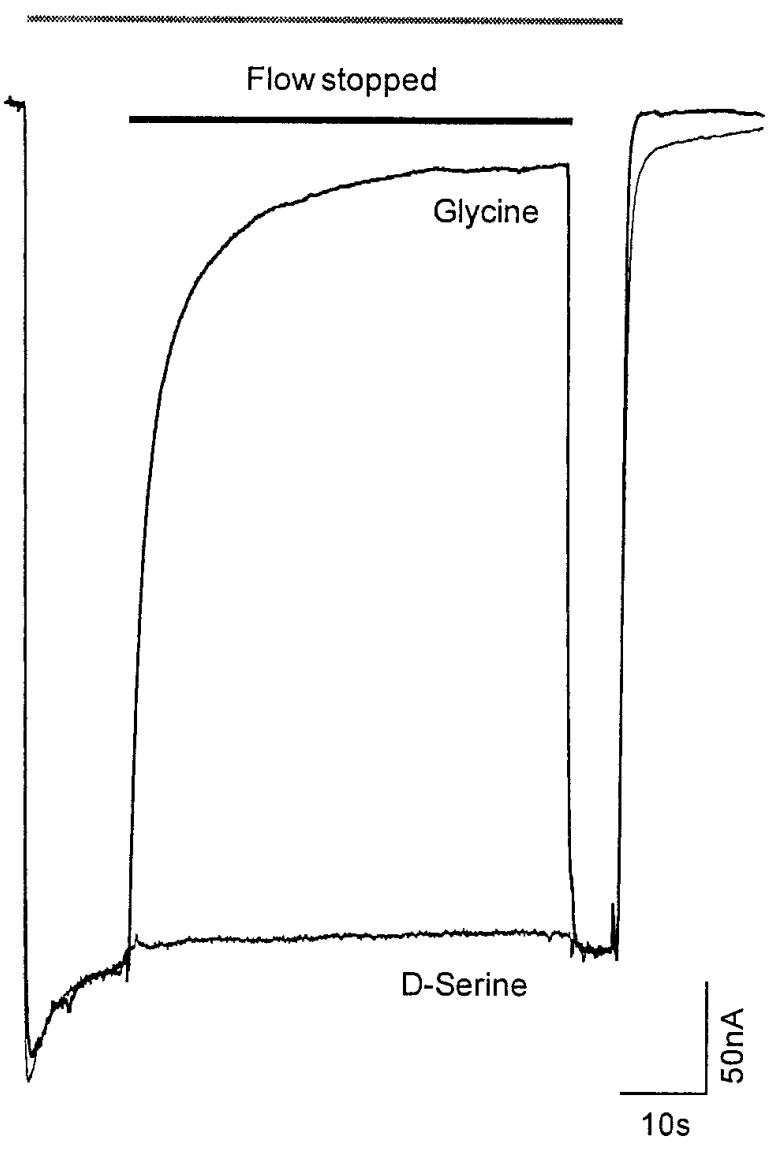

Figure 5. The stopped-flow inhibition of NMDAR in $\mathrm{GLYT}^{+}$oocytes is not observed with $\mathrm{D}$-serine. The current traces recorded in response to the application of $2 \mu \mathrm{M}$ glutamate and either $5 \mu \mathrm{M}$ glycine or D-serine. Stopped-flow inhibition is observed in the presence of glycine but not in the presence of D-serine, which is not transported by GLYT1b but behaves as an agonist of NMDAR.

changes in membrane potential. In $\mathrm{GLYT}^{+}$oocytes, at low glycine concentration $(1 \mu \mathrm{M})$, we observed relaxation of NMDAR currents (background current subtracted) in response to voltage steps (Fig. 9A). For each depolarizing step, the current recorded at the onset of the voltage pulse was smaller than the current recorded 


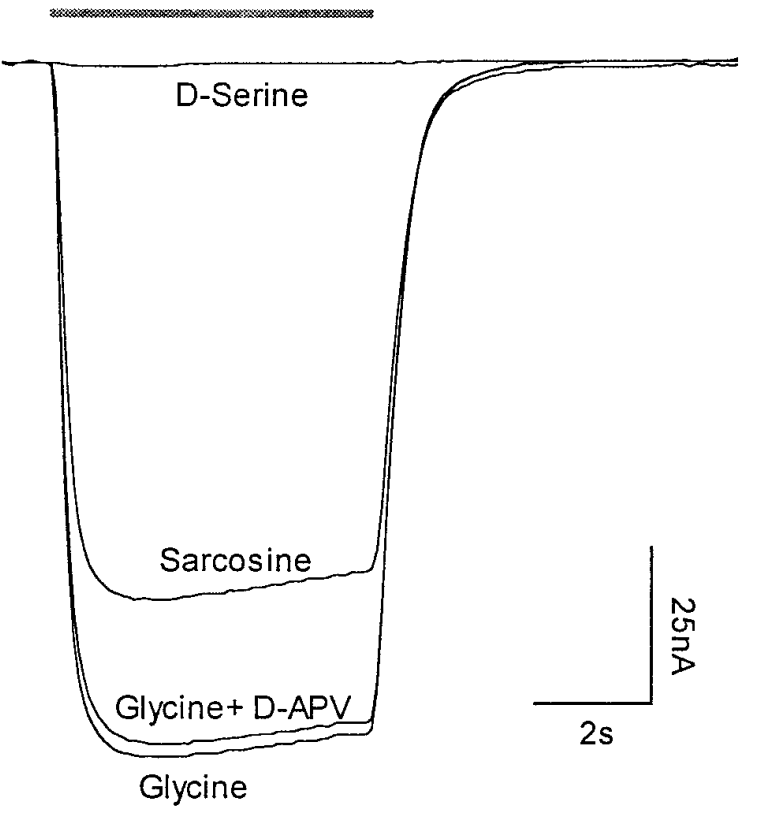

Figure 6. Sarcosine but not D-serine is a substrate for GLYT1b. Transporter current traces recorded from an oocyte expressing only GLYT1b and evoked by the application of $200 \mu \mathrm{M}$ glycine, $200 \mu \mathrm{M}$ sarcosine, $200 \mu \mathrm{M}$ D-serine, and $200 \mu \mathrm{M}$ glycine $+100 \mu \mathrm{M}$ D-APV.

in steady state. As seen in Figure 9B, both the instantaneous (solid squares) and the steady-state (open circles) currents reversed at the same membrane potential, suggesting that the time-activated current is only attributable to an increasing activation of NMDARs. The time constant $(181 \pm 4.2 \mathrm{msec}, n=32, \pm \mathrm{SEM})$ of these relaxations is voltage-independent within this voltage range. Repolarization to the holding potential evoked large inward tail currents, the amplitude of which increased with the magnitude of the voltage step. The peak to steady-state ratio of the NMDAR current depends on $[G l y]_{\mathrm{b}}$ and on the density of transporter expressed in the oocyte membrane. In the results illustrated in Figure $9 C$, this ratio is found to be 12.6 for $[G l y]_{\mathrm{b}}=1 \mu \mathrm{M}$ and decreases to 1.7 for $[G l y]_{\mathrm{b}}=10 \mu \mathrm{M}$. The addition of $100 \mu \mathrm{M}$ D-APV inhibits the NMDAR current and reveals the small uptake current contribution $(4.2 \%$ at $-80 \mathrm{mV})$ to the steady-state total current $(\sim 0.4$ and $2.5 \%$ of the peak NMDAR current at $-100 \mathrm{mV}$ for $[G l y]_{\mathrm{b}}=1 \mu \mathrm{M}$ and $[G l y]_{\mathrm{b}}=10 \mu \mathrm{M}$, respectively). The uptake current is not affected by D-APV, as shown in Figure 6 for an oocyte expressing only GLYT1b, with a mean amplitude of $95 \pm$ $4.8 \%(n=6)$ of the saturating glycine uptake current.

Because these NMDAR current relaxations were neither observed in $\mathrm{GLYT}^{-}$oocytes nor in the presence of D-serine (data not shown), we interpret them as reflecting rapid changes in $[G l y]_{\mathrm{m}}$ attributable to the variation in the rate of glycine uptake. The depolarizing voltage steps reduce the GLYT turnover (Supplisson and Bergman, 1995), thus leading to a $[G l y]_{\mathrm{m}}$ restoration and, accordingly, to a greater activation of NMDARs. The nonlinear $I-V$ relationship of NMDAR current observed in steady state results from alteration of the NMDA conductance at each potential that follows the change in $[G l y]_{\mathrm{m}}$.

\section{Inhibition of NMDAR1-2B in GLYT ${ }^{+}$oocytes}

The inhibition of the NMDA current in $\mathrm{GLYT}^{+}$oocytes is not restricted to NMDARs composed of NR1 and NR2A subunits. It is also observed with NMDARs composed of NR1 and NR2B

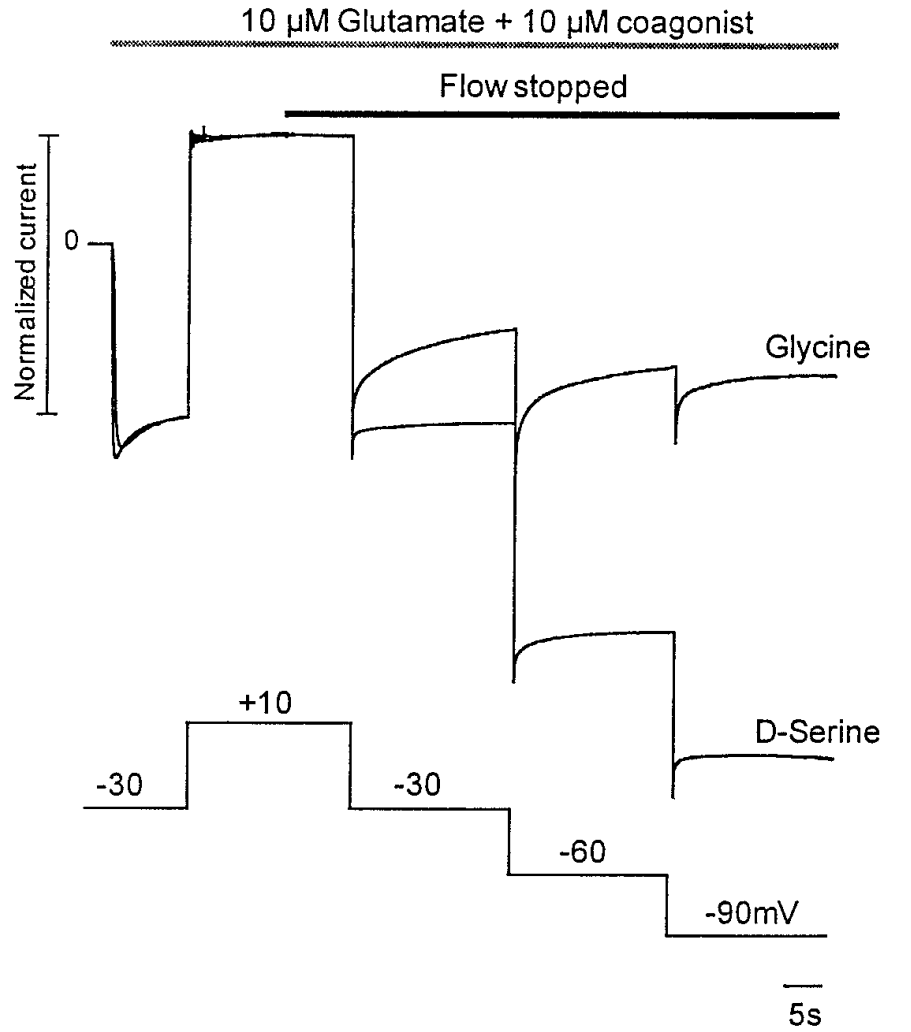

Figure 7. Increase of the stopped-flow inhibition of NMDAR by hyperpolarization. NMDARs were activated in a $\mathrm{GLYT}^{+}$oocyte by the application of $10 \mu \mathrm{M}$ glutamate and either $10 \mu \mathrm{M}$ glycine or D-serine at $V=-30$ $\mathrm{mV}$. Then the membrane voltage was stepped to $+10,-30,-60$, and -90 $\mathrm{mV}$ for $15 \mathrm{sec}$ at each potential. The stopped-flow condition did not induce an inhibition of the NMDA current, because glycine uptake is greatly reduced at $+10 \mathrm{mV}$. For negative voltages, the NMDAR current evoked in the presence of $\mathrm{D}$-serine was stable and increased linearly with voltage, except for a minor rectification observed at $-90 \mathrm{mV}$ that is likely to be attributable to contaminating traces of $\mathrm{Mg}^{2+}$. In the presence of glycine, in contrast, the NMDAR current declined with time at each potential to such levels that the overall increase of the current was much smaller than predicted from the change in driving force.

subunits. These receptors have a glycine affinity (Kutsuwada et al., 1992) closer to that of neuronal receptors (Johnson and Ascher, 1987; Benveniste et al., 1988; Thomson et al., 1989; D'angelo et al., 1990; Thomson, 1990). In three experiments under fast-flow conditions similar to those described in Figure $8 A$, the glycine $\mathrm{EC}_{50}$ of the NMDAR1-2B increases (Fig. 10 $A$ ) from $0.6 \pm 0.09$ (solid circles, $n=3$ ) in $\mathrm{GLYT}^{-}$oocytes to $1.6,1.8$, and $3 \mu \mathrm{M}$ in $\mathrm{GLYT}^{+}$oocytes [for clarity, only the latter experiment is shown (open circles)]. This up to fivefold increase in the glycine $\mathrm{EC}_{50}$ of NMDAR1-2B in GLYT $^{+}$oocyte can be explained by the decrease of $[G l y]_{\mathrm{m}}$ as described previously in Figure $8 D$. This gives a reduction of $[G l y]_{\mathrm{b}}$ by a factor $5\left([G l y]_{\mathrm{m}} \approx[G l y]_{\mathrm{b}} / 5\right)$ in the experiment shows Figure $10 \mathrm{~A}$, which fits in the range determined with NMDAR1-2A in Figure $8 D$. The mean reductions of NMDAR1-2B current in $\mathrm{GLYT}^{+}$oocytes were $71 \pm 17 \%, 50 \pm$ $18 \%, 30 \pm 7.8 \%$, and $11 \pm 2.9 \%(n=3)$ of the control current recorded in $\mathrm{GLYT}^{-}$oocyte $(n=3)$, respectively, at $0.3,1,3$, and $10 \mu \mathrm{M}$ glycine.

To illustrate the capacity of GLYT to control $[G l y]_{\mathrm{m}}$ under fast-flow conditions in a range of $[G l y]_{\mathrm{b}} \sim 100$ times lower than the transporter $\mathrm{EC}_{50}$, we performed relaxation experiments under 

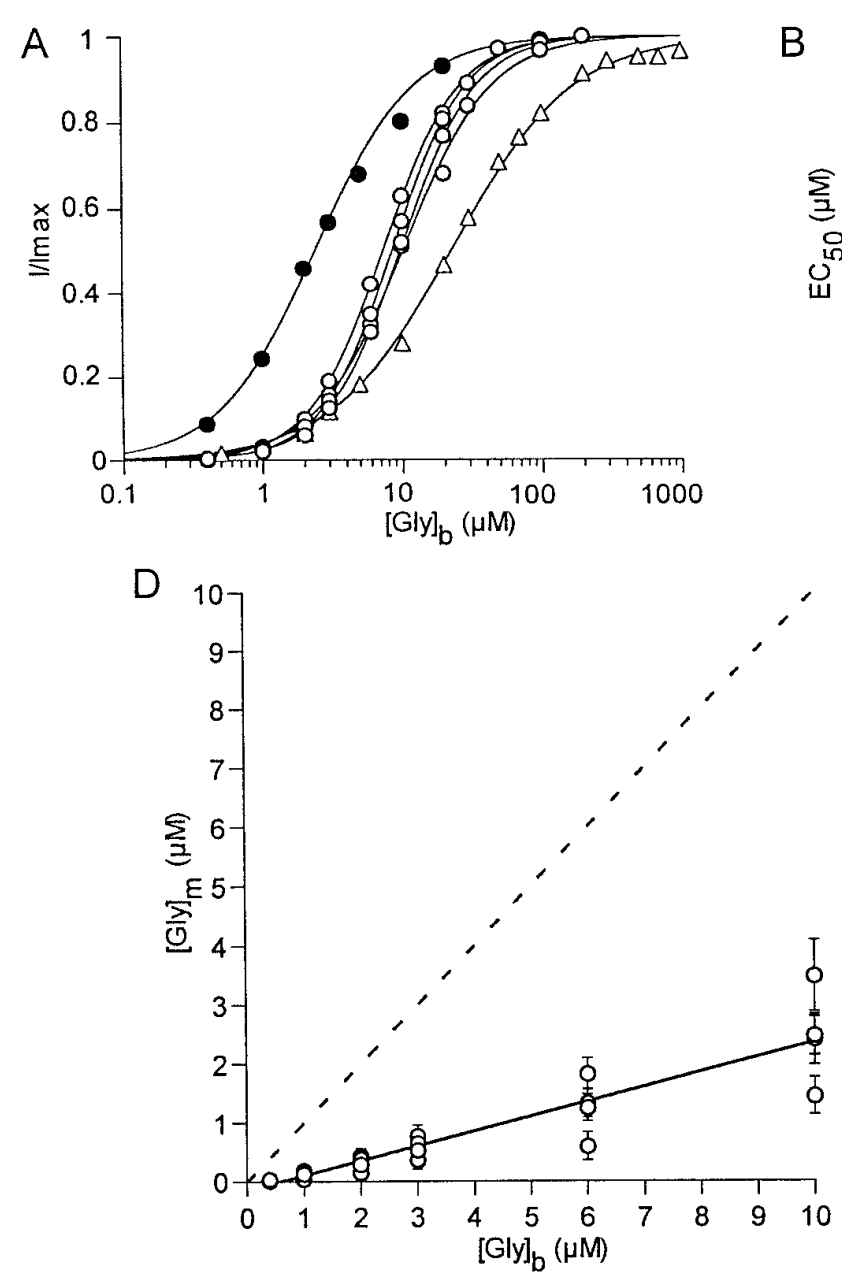
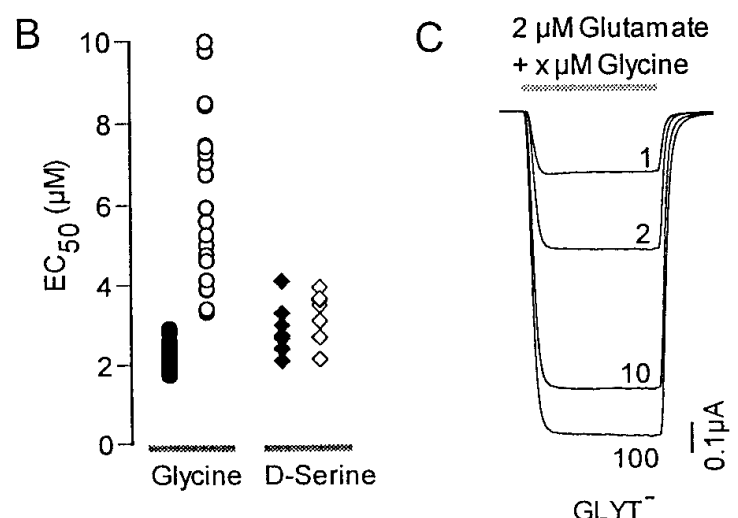

$2 \mu$ MGlutamate

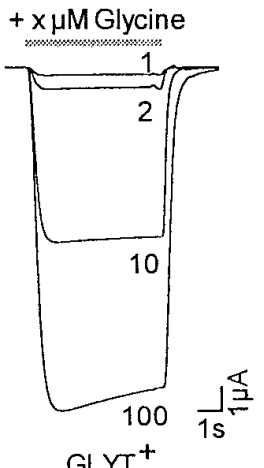
$+x \mu M$ Glycine

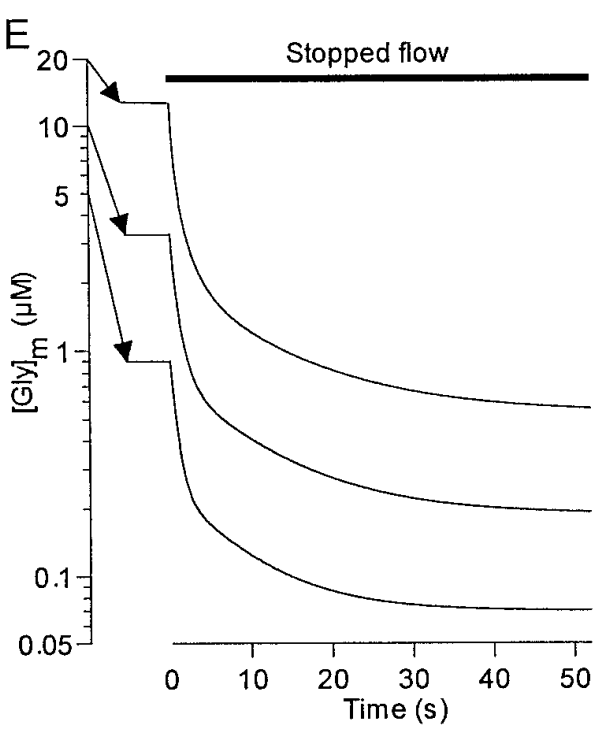

Figure 8. A glycine gradient is maintained by GLYT1b between the bath and the membrane under fast-flow condition in GLYT ${ }^{+}$oocytes. $A$, Glycine concentration-NMDAR current relationship in the presence of 2 or $10 \mu \mathrm{M}$ glutamate in $\mathrm{GLYT}^{-}$oocytes [solid circles, $n=14$, $\mathrm{EC}_{50}=2.3 \pm 0.3 \mu \mathrm{M} ; n_{\mathrm{h}}$ $=1.3 \pm 0.12(\mathrm{SD}), I_{\max }$ ranged from 0.45 to $\left.7 \mu \mathrm{A}\right]$ and $\mathrm{GLYT}^{+}$oocyte (open circles, $\mathrm{EC}_{50}=7.5,8.5,9.8,10.2 \mu \mathrm{M} ; n_{\mathrm{h}}=1.6,1.7,1.6,1.4 ;$ the individual experiments were not averaged, because each $\mathrm{GLYT}^{+}$oocyte expressed GLYT1b at different levels) were fitted according to the Hill equation:

$$
I=\frac{I_{\max }}{1+\left(\frac{\mathrm{EC}_{50}}{[G l y]_{\mathrm{b}}}\right)^{n}},
$$

and then normalized to the maximal current $\left(I_{\max }\right)$ for display. The glycine uptake current dose-response curve is shown for comparison [open triangles, $n=5, \mathrm{EC}_{50}=22.5 \pm 4.1 \mu \mathrm{M}(\mathrm{SD}), n_{\mathrm{h}}=1$, experiments performed with oocytes expressing only GLYT1b]. The EC E0 $_{50}$ for GLYT1b is in good agreement with the value reported for high-affinity glycine uptake in hippocampal slices (Fedele and Foster, 1992). Error bars indicate SEM. $B$, Summary of glycine $\mathrm{EC}_{50}$ values (solid circles, open circles), and D-serine $\mathrm{EC}_{50}$ values (solid diamonds, open diamonds) of NMDARs measured in GLYT ${ }^{-}$oocytes [solid circles $(n=19)$, solid diamonds $(n=8)]$ and GLYT ${ }^{+}$oocytes [open circles $(n=22)$, open diamonds $\left.(n=7)\right]$. Glycine $\mathrm{EC}_{50}$ values differ significantly in GLYT $^{-}$ and GLYT ${ }^{+}$oocytes, with $p=510^{-10}(F$ test). $C$, Current traces showing that the reduction of NMDAR current under fast-flow conditions is established rapidly. The NMDAR currents were activated repeatedly by $5 \mathrm{sec}$ applications of solutions containing $2 \mu \mathrm{M}$ glutamate and various concentrations of glycine to GLYT ${ }^{-}$oocytes (left) or to GLYT ${ }^{+}$oocytes (right). Current traces were normalized to the maximal current. $D$, Estimate of the $[G l y]_{\mathrm{m}}$. For each $[G l y]_{\mathrm{b}}$ shown in $A$, the effective $[G l y]_{\mathrm{m}}$ sensed by the NMDARs in $\mathrm{GLYT}^{+}$oocytes was extracted from the Hill equation and the values of glycine $\mathrm{EC}_{50}$ and Hill coefficient measured in GLYT ${ }^{-}$oocytes. The dashed line refers to $[G l y]_{\mathrm{m}}=[G l y]_{\mathrm{b}}$. The error bars indicate the estimated error on $[G l y]_{\mathrm{m}}$ as calculated from the SD. E, Semilogarithmic plot of $[G l y]_{\mathrm{m}}$ during the stopped-flow condition for three repeated experiments with $[G l y]_{\mathrm{b}}=5,10$, and 20 $\mu \mathrm{M}$ in the presence of $10 \mu \mathrm{M}$ glutamate $(V=-100 \mathrm{mV})$. [Gly $]_{\mathrm{m}}$ was estimated under fast-flow conditions corresponding to $t=0$, as described above, and the arrows indicate the initial $\Delta[\mathrm{Gly}]$ values. $[G l y]_{\mathrm{m}}$ was calculated as a function of time from the NMDAR current ratio $\left.I_{(\mathrm{t})} / I_{(\mathrm{t}}=0\right)$.

fast-flow conditions with oocytes expressing NR1-NR2B subunits. Figure $10 B$ shows that the NMDA current evoked in the GLYT ${ }^{-}$ oocyte in response to $0.3 \mu \mathrm{M}$ glycine and $2 \mu \mathrm{M}$ glutamate is time-independent when the membrane potential is stepped from a holding potential $\left(V_{\mathrm{H}}\right)$ of $-40 \mathrm{mV}$ to a test potential $\left(V_{\mathrm{T}}\right)$ ranging from -100 to $+40 \mathrm{mV}$. When the membrane is repolarized from $V_{\mathrm{H}}=+40 \mathrm{mV}$ to $V_{\mathrm{T}}=-100 \mathrm{mV}$, a brief relaxation (varying from trace to trace) is observed that may involve an effect of positive potential to the open-state probability of NMDAR (Nowak and Wright, 1992; Li-Smerin and Johnson, 1996). In contrast, the NMDAR current recorded in $\mathrm{GLYT}^{+}$oocyte displays a marked time dependence at all potentials. For $V_{\mathrm{T}}<V_{\mathrm{H}}$, the current size increases instantaneously as expected from the change in driving force for the NMDAR channel, then declines as $[G l y]_{\mathrm{m}}$ decreases because of the rise in driving force for the glycine uptake. For $V_{\mathrm{T}}>V_{\mathrm{H}}$, the NMDAR current increases with time as 


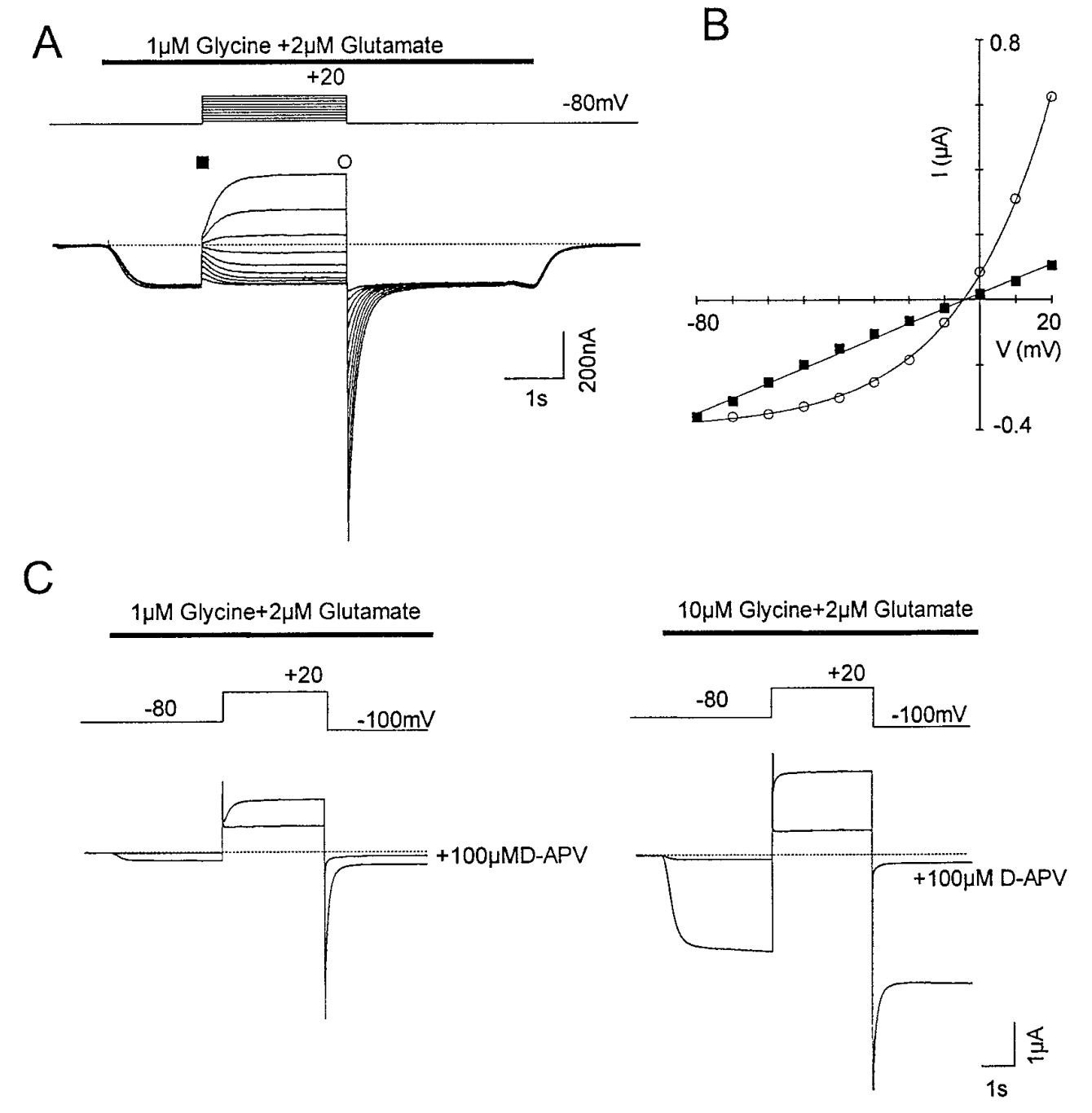

Figure 9. Relaxation of NMDAR currents induced by voltage steps in $\mathrm{GLYT}^{+}$oocytes under fast-flow superfusion. $A$, Time course of NMDAR current traces evoked by the application of $1 \mu \mathrm{M}$ glycine and $2 \mu \mathrm{M}$ glutamate at $V_{\mathrm{H}}=-80 \mathrm{mV}$. During each successive agonist application (repeated at $20 \mathrm{sec}$ intervals), a $2.5 \mathrm{sec}$ voltage step was applied, between +20 and $-70 \mathrm{mV}$. The background current determined from the same protocol in the absence of agonist has been subtracted from the total current recorded in the presence of agonist. $B$, Current-voltage relationships of the instantaneous (solid squares) and the steady-state (open circles) NMDAR current obtained as indicated in $A$. $C$, Time course of NMDAR current traces evoked by the application of $1 \mu \mathrm{M}$ (left) or $10 \mu \mathrm{M}$ (right) glycine and $2 \mu \mathrm{M}$ glutamate in the absence and in the presence of $100 \mu \mathrm{M}$ D-APV. Leakage current is not subtracted.

$[G l y]_{\mathrm{m}}$ rises because of a smaller driving force for the glycine transport.

A more quantitative description of the effects of membrane potential changes on NMDAR1-2B is shown in Figure 11, where the background current has been subtracted from the total current. The protocol is similar to that described in Figure $9 A$. The off-relaxation time constant is $477 \pm 7.2 \mathrm{msec}(n=33, \pm$ SEM $)$ and appears to be voltage-independent. It is significantly larger $(p<0.0001)$ than with NMDAR1-2A and might reflect the difference in glycine affinity of the NR2A and NR2B subunits (Monyer et al., 1992; Paoletti et al., 1995). The current-voltage relationship in Figure $11 B$ shows that both instantaneous (solid squares) and steady-state (open circles) currents have the same reversal potential. When the membrane potential is repolarized to $V_{\mathrm{H}}=-80 \mathrm{mV}$, the instantaneous (solid triangles) change in the current size is only attributable to a variation in the driving force for the NMDA current as demonstrated by the common reversal potential. Alteration of the NMDAR conductance can be attributed to only a change in the receptor activation by variations in $[G l y]_{\mathrm{m}}$.

The uptake current of the transporter itself was also sensitive to the stopped-flow condition (Fig. $2 A$ ), suggesting that studies of transporters with high levels of expression and/or slow superfusion may often be complicated by local substrate depletion (our unpublished observations).

\section{DISCUSSION}

\section{Control of the $[G / y]_{m}$ by GLYT1b}

The main purpose of the present study was to develop an experimental model permitting us to test the hypothesis formulated in recent papers (see introductory remarks) that membrane transporters could efficiently regulate the extracellular concentration in substrates at the level of their membrane targets in relative independence of the nominal concentration of the same substrates in the bulk solution. The basic idea was that in most biological systems, the solute molecules en route to the membrane have to face restricted diffusion barriers limiting small phenomenological compartments in which fine regulation can take place and have a physiological relevance.

In mature Xenopus oocytes, membrane capacitance measurements have revealed that the membrane area is $\sim 8$ times larger than expected for a smooth sphere of the same apparent diameter (assuming a specific capacitance of $1 \mu \mathrm{F} / \mu \mathrm{m}^{2}$ ). On the basis of morphological studies, this excess in membrane area can be explained by the presence of numerous $\left(6-7 \mu \mathrm{m}^{2}\right)$ small $(1-2 \mu \mathrm{m})$ microvilli at the oolemma (Zampighi et al., 1995). According to this view, it is likely that between adjacent microvilli, the external space is shaped as small compartments in which solute diffusion is somehow restricted. If specific transporters are expressed at the 

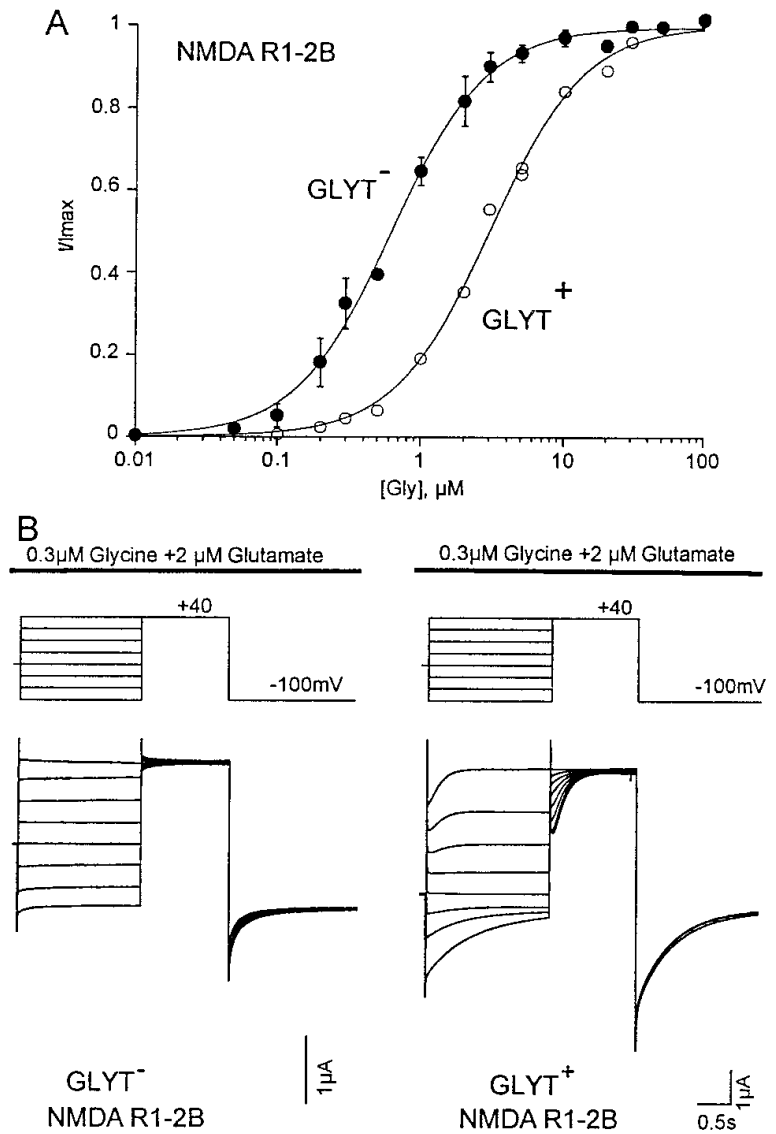

Figure 10. Reduction and relaxation of NMDAR1-2B current in $\mathrm{GLYT}^{+}$oocyte under fast-flow condition. A, Glycine concentrationNMDAR current relationship in the presence of $2 \mu \mathrm{M}$ glutamate in $\mathrm{GLYT}^{-}$oocytes [solid circles, $n=3, \mathrm{EC}_{50}=0.6 \pm 0.1 \mu \mathrm{M} ; n_{\mathrm{h}}=1.3 \pm 0.2$ (SD)] and GLYT ${ }^{+}$oocyte (open circles, $\mathrm{EC}_{50}=3 \mu \mathrm{M} ; n_{\mathrm{h}}=1.3$ ). B, Relaxation of NMDAR1-2B currents induced by voltage steps in GLYT ${ }^{-}$ (left) and $\mathrm{GLYT}^{+}$(right) oocytes under fast-flow superfusion. NMDARs are activated by the application of $0.3 \mu \mathrm{M}$ glycine and $2 \mu \mathrm{M}$ glutamate at $V_{\mathrm{H}}=-40 \mathrm{mV}$. During each successive agonist application (repeated at 20 sec intervals), a $1.25 \mathrm{sec}$ voltage step is applied (voltage step protocol is drawn at top of the current traces). Leakage current is not subtracted.

membrane surface, a fine regulation of the concentration of their preferred substrate thus could take place. We assume that in our model, NMDAR and GLYT1b proteins are distributed evenly at the surface of the oocyte including the microvilli.

The interpretation above is based primarily on the following results: the NMDAR current response to glutamate in the presence of glycine is reduced markedly when the circulation of the superfusing solution is stopped abruptly. This does not occur (1) in oocytes in which GLYT1b was not expressed; (2) when the GLYT1b is inhibited by substituting $\mathrm{Li}^{+}$for $\mathrm{Na}^{+}$in the external medium; (3) when glycine is replaced by D-serine in the external medium; (4) when GLYT1b is saturated by sarcosine; or (5) when membrane voltage changes alter the carrier function.

Finally, we show a significant NMDAR current reduction resulting from glycine uptake by GLYT1b even if the superfusion flow is very fast. In other words, we demonstrate that when expressed at the surface of a restricted diffusion space, NMDAR are more or less, but always, influenced by the local control in glycine concentration exerted by GLYT1b. This view likely holds for synapses in the CNS.

It should be noticed that the active uptake produces an equal extracellular depletion and intracellular accumulation (in terms of transferred amount of substrate) but not an equivalent change in concentration on either side of the membrane. Moreover, on the external side of the membrane (and likely in the restricted diffusion space) the cell uptake is counterbalanced by the passive diffusion of the substrate from the bath so that a concentration gradient is set up across a diffusion barrier.

This effect of active transport, in combination with the presence of a large, unstirred layer, has been reviewed extensively for the epithelia by Barry and Diamond (1984). In Xenopus oocyte, the vitelline envelope has a thickness of 1-5 $\mu \mathrm{M}$ (Wolf et al., 1976) but generates an apparent unstirred layer of $\mathrm{d}=\sim 11 \mu \mathrm{m}$, which appears as the limiting factor for a rapid exchange of external solution (Costa et al., 1994). We propose that the glycine gradient takes place across this unstirred layer (including the microvilli space) during fast perfusion.

The steady-state glycine flux across this diffusion barrier should equal the transport flux:

$$
P_{\mathrm{Gly}}\left([G l y]_{\mathrm{b}}-[G l y]_{\mathrm{m}}\right)=\frac{J_{\max }[G l y]_{\mathrm{m}}}{[G l y]_{\mathrm{m}}+K_{\mathrm{m}}},
$$

where $J_{\max }$ is the maximal glycine uptake flux, which can be estimated from the uptake current:

$$
J_{\max }=\frac{I_{\max }}{z F S}\left(\mathrm{nmole} /\left(\mathrm{cm}^{2} \mathrm{sec}\right)\right),
$$

where $I_{\max }$ is the maximal uptake current (nA), F is the Faraday's constant, $z$ is the number of charges transferred by molecules of glycine ( $z=1$, assuming a coupling of $2 \mathrm{Na}^{+} / \mathrm{Cl}^{-} /$glycine), and $S$ is the spherical apparent surface of the oocyte $\left(S \approx 0.031 \mathrm{~cm}^{2}\right) . K_{\mathrm{m}}$ is the apparent affinity of GLYT1b for glycine $\left(K_{\mathrm{m}}=22 \mu \mathrm{M}\right.$; see Fig. $8 A) ; P_{\mathrm{Gly}}(\mathrm{cm} / \mathrm{sec})$ is the permeability coefficient for glycine across the diffusion barrier of the oocyte.

From that relationship, $[G l y]_{\mathrm{m}}$ can be deduced as

$$
[G l y]_{\mathrm{m}}=\left([G l y]_{\mathrm{b}}-\alpha+\sqrt{\left([G l y]_{\mathrm{b}}-\alpha\right)^{2}+4[G l y]_{\mathrm{b}} K_{\mathrm{m}}}\right) / 2,
$$

with $\alpha=J_{\text {max }} / /_{\text {Gly }}+K_{\mathrm{m}}$, in $\mu \mathrm{M}$.

The fit of $[G l y]_{\mathrm{m}}$ as a function of $[G l y]_{\mathrm{b}}$ is shown in Figure 12 in a semilogarithm scale, with $K_{\mathrm{m}}$ fixed at $22 \mu \mathrm{M}$. The fitted $\alpha$ values were 72 (open squares), 100 (open triangles), 102 (inverted triangles), and 176 (open circles) $\mu \mathrm{M}$. From typical $I_{\max }$ amplitudes, ranging from 20 to $300 \mathrm{nA}$, determined in nine experiments performed under similar conditions, we estimate $P_{\mathrm{Gly}}$ to be approximately five $10^{-4} \mathrm{~cm} / \mathrm{sec}$. This leads to $I_{\max }=76,120,120$, and $235 \mathrm{nA}$, respectively, for the four experiments shown in Figure 12. This permeability is approximately one tenth of the predicted glycine permeability in water for an unstirred layer of 11 $\mu \mathrm{M}\left(P_{\mathrm{Gly}}=D_{\mathrm{Gly}} / \mathrm{d}=510^{-3} \mathrm{~cm} / \mathrm{sec}\right.$, with $D_{\mathrm{Gly}}=510^{-6} \mathrm{~cm}^{2} / \mathrm{sec}$ and $\left.d=1.110^{-3} \mathrm{~cm}\right)$. Figure 12 shows that there is good agreement between the experimental data and the prediction of the model. In some experiments, however, we found that at low $[G l y]_{\mathrm{b}},[G l y]_{\mathrm{m}}$ was lower than predicted by Equation 4. This deviation might reflect particular constraints attributable to the presence of microvilli in the restricted diffusion barrier that could arise, for instance, from the presence of GLYT1b altering $[G l y]_{\mathrm{m}}$ along the microvilli. At higher $[G l y]_{\mathrm{b}}$, the transporters could be saturated so that the effect of their spatial distribution along the microvilli should appear negligible.

Concerning the relaxation experiments, it is worth noting that a depolarizing pulse induces a rise in glycine concentration that 
A

\section{$0.3 \mu \mathrm{M}$ Glycine $+2 \mu \mathrm{M}$ Glutamate}
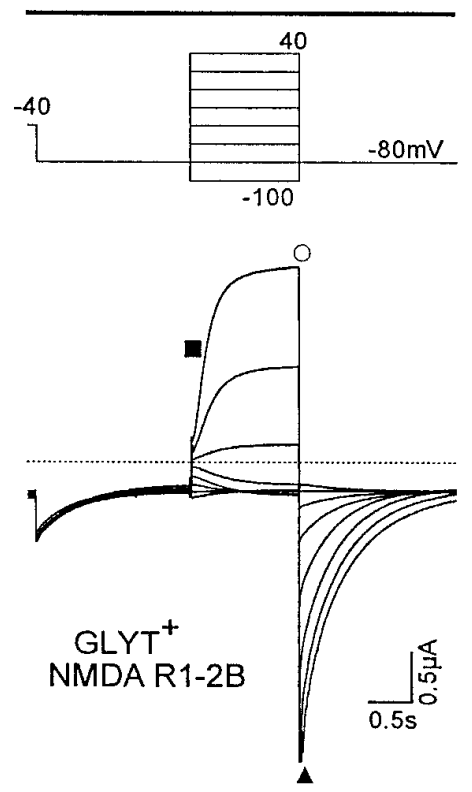

B

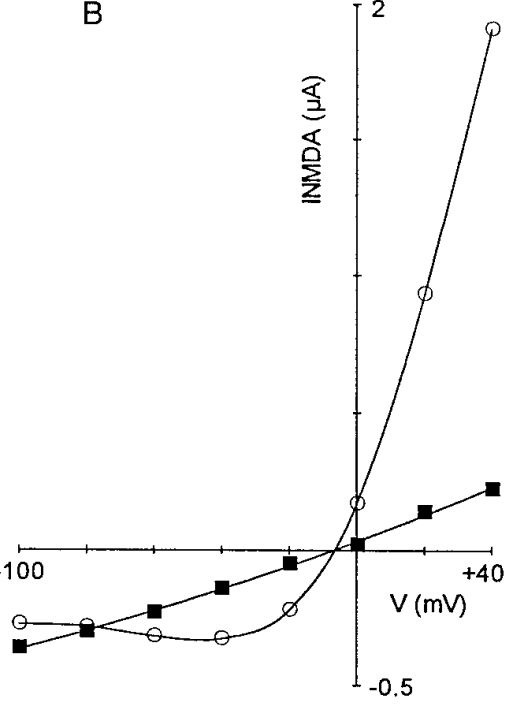

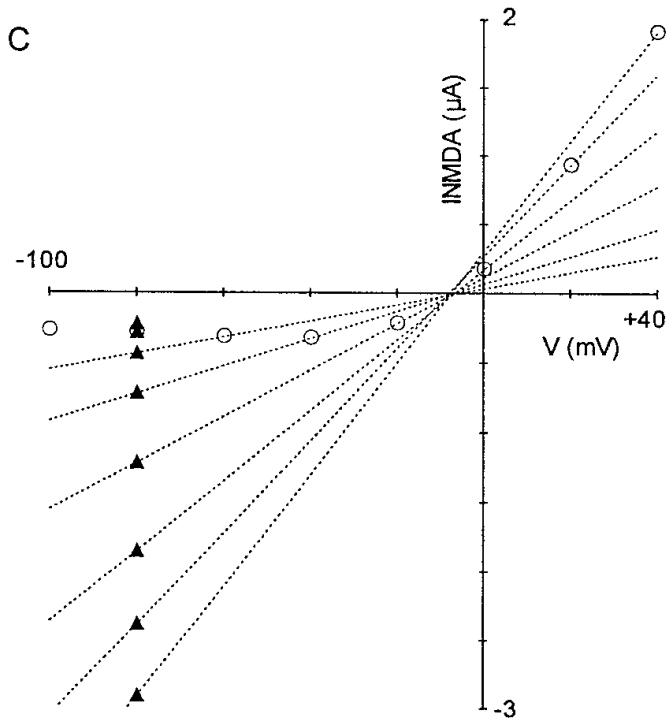

Figure 11. Relaxation of NMDAR1-2B currents induced by voltage steps in GLYT ${ }^{+}$oocytes under fast-flow superfusion. $A$, Time course of NMDAR1-2B current traces evoked by the application of $0.3 \mu \mathrm{M}$ glycine and $2 \mu \mathrm{M}$ glutamate at $V_{\mathrm{H}}=-80 \mathrm{mV}$. During each successive agonist application (repeated at 20 sec intervals), a $1.25 \mathrm{sec}$ voltage step was applied, between +40 and $-100 \mathrm{mV}$. The background current, determined from the same protocol in the absence of agonist, has been subtracted from the total current recorded in the presence of agonist. B, Current-voltage relationships of the instantaneous (solid squares) and the steady-state (open circles) NMDAR currents obtained as indicated in $A$. $C$, Current-voltage relationships of the steady-state (open circles) and instantaneous (solid triangles) NMDAR currents on repolarization to the holding potential obtained as indicated by the symbols in $A$.

should be governed mostly by glycine diffusion from the bath. As expected, the time constants of the on-relaxation are voltageindependent and of the same magnitude as the time-constant of NMDA activation current by glycine. The time constants measured with NMDA NR1-2A and NR1-2B subunits are not significantly different. In contrast, when the membrane was hyperpolarized, leading to a decrease in $[G l y]_{\mathrm{m}}$ by the transporter, we found that the off-relaxation of the time constant was 188 and 477 msec for NMDAR1-2A and NMDAR1-2B, respectively. These values are comparable with the glycine off-relaxation time constants of $147 \pm 15 \mathrm{msec}$ for NR1-2A (Monyer et al., 1992) and 485 msec for NR1-2B subunits (Paoletti et al., 1995) found for NMDAR expressed in HEK-cells. This suggests to us that the decay of the relaxation most likely reflects the slow dissociation of glycine from NMDAR rather than the actual time course of glycine depletion in the extracellular space.

Under stopped-flow conditions, we postulate that the thickness of the unstirred layer increases and that the glycine gradient extends over a larger scale. The theoretical limit for the decrease of the external glycine concentration is imposed by the thermodynamics of the transport, as defined by the relation (Attwell and Bouvier, 1992; Attwell et al., 1993):

$$
\frac{[G l y]_{\mathrm{m}}}{[G l y]_{\mathrm{i}}}=\left(\frac{[\mathrm{Na}]_{\mathrm{i}}^{2}[\mathrm{Cl}]_{\mathrm{i}}}{[\mathrm{Na}]_{\mathrm{o}}^{2}[\mathrm{Cl}]_{\mathrm{o}}}\right) e^{\frac{F V}{R T}} .
$$

Assuming $[\mathrm{Na}]_{\mathrm{i}}=10 \mathrm{~mm}$ and $[\mathrm{Cl}]_{\mathrm{i}}=30 \mathrm{~mm},(F, R$, and $T$ have their usual meanings), this ratio is $1.510^{-4}$ at $V=-70 \mathrm{mV}$ and $5.810^{-5}$ at $V=-100 \mathrm{mV}$. Our estimated values of $[G l y]_{\mathrm{m}}$ under stopped-flow conditions shown in Figure $8 B$ are compatible with an intracellular concentration of free glycine $\leq 1 \mathrm{~mm}$. It should be noted that under our experimental condition, the equilibrium is never obtained, because a steady-state inward flux is present between the bath and the oocyte cytoplasm.

\section{Physiological implications}

Our results indicate that the glycine transporter expressed in Xenopus oocytes is able to deplete glycine near the membrane to concentrations well below $1 \mu \mathrm{M}$ (i.e., the saturating concentration for neuronal NMDARs) when the bath concentration is similar (within a range of 1-10 $\mu \mathrm{M}$ ) to that of CSF. The extrapolation of this conclusion to glutamatergic synapses requires knowledge (not available at this time) of the actual density and distribution of the transporters in the synaptic region. The number of transporters expressed in $\mathrm{GLYT}^{+}$oocytes is of the order of $3.10^{9}-6.10^{10}$ (for a maximal uptake current of 10-200 nA and a turnover of $17 e / \mathrm{sec}$ at $V=-70 \mathrm{mV}$, (S. Supplisson, unpublished data). This allows an estimate of the transporter's density in our experiments of $\sim 150$ 3000 transporters $/ \mu \mathrm{m}^{2}$, a standard value for heterologous expression of transporters in oocytes (Mager et al., 1993; Zampighi et al., 1995). This density is probably higher than that estimated in nervous tissue, but the synaptic extracellular space under the control of neural transporters is much smaller, and thus a lower density of transporters might suffice to produce a similar effect.

Our results show that glycine transporters, when expressed in a restricted diffusion space, are capable of desaturating the glycinesite of NMDARs and thus of depressing the glutamatergic transmission. This interpretation is now supported by the results obtained in hippocampal slices indicating that addition of $10 \mu \mathrm{M}$ glycine in the Ringer's solution increase by $73 \%$ the excitatory postsynaptic currents mediated by NMDARs (Wilcox et al., 1996). A release of glycine [by reverse transport (Attwell and Bouvier, 


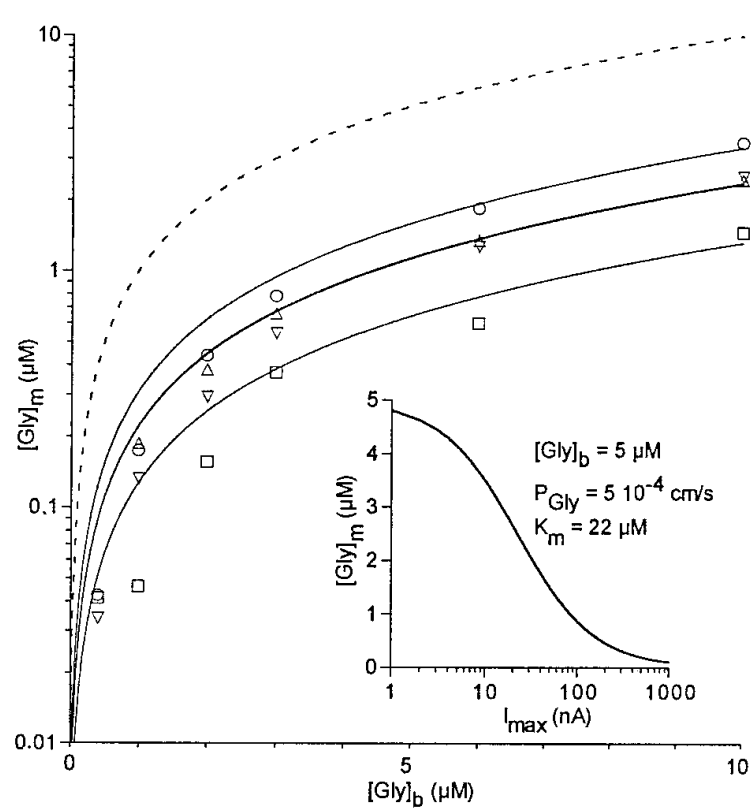

Figure 12. Fit of $[G l y]_{\mathrm{m}}$ in a logarithmic scale as a function of $[G l y]_{\mathrm{b}}$ using Equation 4. The experimental $[G l y]_{\mathrm{m}}$ are those reported in Figure $8 D$. The dashed line reflects $[G l y]_{\mathrm{m}}=[G l y]_{\mathrm{b}}$. The solid lines are the fitted curve (see text). The insert represents the predicted change of $[G l y]_{\mathrm{m}}$ as a function of $I_{\max }$, in a logarithmic scale, for $[G l y]_{\mathrm{b}}=5 \mu \mathrm{M}, P_{\mathrm{Gly}}=510^{-4} \mathrm{~cm} / \mathrm{sec}$, and $K_{\mathrm{m}}$ $=22 \mu \mathrm{M}$.

1992) or by liberation at nearby glycinergic synapses] or D-serine [by the astrocytes (Schell et al., 1995, 1997)] would reinforce the glutamatergic transmission. This strengthens the notion that either glycine (Johnson and Ascher, 1987; Thomson 1990; Kemp and Leeson, 1993) or D-serine (Thiels et al., 1992; Matsui et al., 1995; Schell et al., 1995, 1997) can play a physiological role as excitatory neuromodulators at glutamatergic synapses.

\section{REFERENCES}

Adams RH, Sato K, Shimada S, Tohyama M, Püschel AW, Betz H (1995) Gene structure and glial expression of the glycine transporter GLYT1 in embryonic and adult rodents. J Neurosci 15:2524-2532.

Ascher P (1990) Measuring and controlling the extracellular glycine concentration at the NMDA receptor level. Exp Med Biol Adv 268:13-16.

Attwell D, Bouvier M (1992) Cloners quick on the uptake. Curr Biol 2:541-543.

Attwell D, Barbour B, Szatkowski M (1993) Nonvesicular release of neurotransmitter. Neuron 11:401-407.

Barbour B, Keller BU, Llano I, Marty A (1994) Prolonged presence of glutamate during excitatory synaptic transmission to cerebellar Purkinje cells. Neuron 12:1331-1343.

Barry PH, Diamond JM (1984) Effects of unstirred layers on membrane phenomena. Physiol Rev 64:763-872.

Benveniste M, Clements J, Vyklický LJ, Mayer ML (1990) A kinetic analysis of the modulation of $N$-methyl-D-aspartic acid receptors by glycine in mouse cultured hippocampal neurones. J Physiol (Lond) 428:333-357.

Brew H, Attwell D (1987) Electrogenic glutamate uptake is a major current carrier in the membrane of axolotl retinal glial cells. Nature 327:707-709.

Costa ACS, Patrick J, Dani JA (1994) Improved technique for studying ion channels expressed in Xenopus oocytes, including fast superfusion. Biophys J 67:395-401.

D'angelo E, Rossi P, Garthwaite J (1990) Dual-component NMDA receptor currents at a single central synapse. Nature 346:467-470.

Fedele E, Foster AC (1992) $\left[{ }^{3} \mathrm{H}\right]$ glycine uptake in rat hippocampus: kinetic analysis and autoradiographic localization. Brain Res 572:154-163.

Guastella J, Brecha N, Weigmann C, Lester HA, Davidson N (1992)
Cloning, expression, and localization of a rat brain high-affinity glycine transporter. Proc Natl Acad Sci USA 89:7189-7193.

Johnson JW, Ascher P (1987) Glycine potentiates the NMDA response in cultured mouse brain neurons. Nature 325:529-531.

Kemp JA, Leeson PD (1993) The glycine site of the NMDA receptorfive years on. Trends Pharmacol Sci 14:20-25.

Kim KM, Kingsmore SF, Han H, Yang-Feng TL, Godinot N, Seldin MF, Caron MG, Giros B (1994) Cloning of the human glycine transporter type 1: molecular and pharmacological characterization of novel isoform variants and chromosomal localization of the gene in the human and mouse genomes. Mol Pharmacol 45:608-617.

Kleckner NW, Dingledine R (1988) Requirement for glycine in activation of NMDA-receptor expressed in Xenopus oocyte. Science 241:835-837.

Kupper J, Ascher P, Neyton J (1996) Probing the pore region of recombinant NMDA channels using external and internal magnesium block. Proc Natl Acad Sci USA 93:8648-8653.

Kutsuwada T, Kashiwabuchi N, Mori H, Sakimura K, Kushiya E, Araki K, Meguro H, Masaki H, Kumanishi T, Arakawa M, Mishina M (1992) Molecular diversity of the NMDA receptor channel. Nature 358:36-41.

Leonard JP, Kelso SR (1990) Apparent desensitization of NMDA responses in Xenopus oocytes involves calcium-dependent chloride current. Neuron 4:53-60.

Li-Smerin Y, Johnson JW (1996) Effects of intracellular $\mathrm{Mg}^{2+}$ on channel gating and steady-state responses of the NMDA receptor in cultured rat neurons. J Physiol (Lond) 491:137-150.

Liu QR, Lopez-Corcuera B, Mandiyan S, Nelson H, Nelson N (1993) Cloning and expression of a spinal cord- and brain-specific glycine transporter with novel structural features. J Biol Chem 268:22802-22808.

Luque JM, Nelson N, Richards JG (1995) Cellular expression of glycine transporter 2 messenger RNA exclusively in rat hindbrain and spinal cord. Neuroscience 64:525-535.

Mager S, Naeve J, Quick M, Labarca C, Davidson N, Lester HA (1993) Steady states, charge movements, and rates for a cloned GABA transporter expressed in Xenopus oocytes. Neuron 10:177-188.

Matsui T, Sekiguchi M, Hashimoto A, Tomita U, Nishikawa T, Wada K (1995) Functional comparison of D-serine and glycine in rodents: the effect on cloned NMDA receptors and the extracellular concentration. J Neurochem 65:454-458.

Monyer H, Sprengel R, Schoepfer R, Herb A, Higuchi M, Lomeli H, Burnashev N, Sakmann B, Seeburg PH (1992) Heteromeric NMDA receptors: molecular and functional distinction of subtypes. Science 256:1217-1221.

Moriyoshi K, Masu M, Ishii T, Shigemoto R, Mizuno N, Nakanishi S (1991) Molecular cloning and characterization of the rat NMDA receptor. Nature 354:31-37.

Nicholson C (1995) Interaction between diffusion and Michaelis-Menten uptake of dopamine after iontophoresis in striatum. Biophys $\mathrm{J}$ 68:1699-1715.

Nowak LM, Wright JM (1992) Slow voltage-dependent changes in channel open-state probability underlies hysteresis of NMDA responses in $\mathrm{Mg}^{2+}$-free solutions. Neuron 8:181-187.

Paoletti P, Neyton J, Ascher P (1995) Glycine-independent and subunitspecific potentiation of NMDA responses by extracellular $\mathrm{Mg}^{2+}$. Neuron 15:1109-1120.

Schell MJ, Molliver ME, Snyder SH (1995) D-serine, an endogenous synaptic modulator: localization to astrocytes and glutamate-stimulated release. Proc Natl Acad Sci USA 92:3948-3952.

Schell MJ, Brady RO, Molliver ME, Snyder SH (1997) D-serine as neuromodulator: regional and developmental localizations in rat brain glia resemble NMDA receptors. J Neurosci 17:1604-1615.

Smith KE, Borden LA, Hartig PR, Branchek T, Weinshank RL (1992) Cloning and expression of a glycine transporter reveal colocalization with NMDA receptors. Neuron 8:927-935.

Supplisson S, Bergman C (1995) Charge movement associated with glycine uptake. Soc Neurosci Abstr 21:2063.

Supplisson S, Neyton J, Paoletti P, Bergman C, Ascher P, Teichberg V (1994) Modulation of NMDA-induced currents by a glycine transporter coexpressed with a NMDA receptor in Xenopus oocyte. Soc Neurosci Abstr 20:919.

Thiels E, Weisz DJ, Berger TW (1992) In vivo modulation of $N$-methyl$\mathrm{D}$-aspartate receptor-dependent long-term potentiation by the glycine modulatory site. Neuroscience 46:501-509.

Thomson AM (1990) Glycine is a coagonist at the NMDA receptor/ channel complex. Prog Neurobiol 35:53-74. 
Thomson AM, Walker VE, Flynn DM (1989) Glycine enhances NMDAreceptor mediated synaptic potentials in neocortical slices. Nature 338:422-424.

Tong G, Jahr CE (1994) Block of glutamate transporters potentiates postsynaptic excitation. Neuron 13:1195-1203.

Tsuzuki K, Mochizuki S, Iino M, Mori H, Mishina M, Ozawa S (1994) Ion permeation properties of the cloned mouse epsilon 2/zeta 1 NMDA receptor channel. Brain Res Mol Brain Res 26:37-46.

Westergren I, Nystrom B, Hamberger A, Nordborg C, Johansson BB (1994) Concentrations of amino acids in extracellular fluid after opening of the blood-brain barrier by intracarotid infusion of protamine sulfate. J Neurochem 62:159-165.

Wilcox KS, Maki Fitzsimonds R, Johnson B, Dichter MA (1996) Glycine regulation of synaptic NMDA receptors in hippocampal neurons. J Neurophysiol 76:3415-3424.

Wolf DP, Nishihara T, West DM, Wyrick RE, Hedrick JL (1976) Isolation, physicochemical properties, and the macromolecular composition of the vitelline and fertilization envelopes from Xenopus laevis eggs. Biochemistry 15:3671-3678.

Zafra F, Aragon C, Olivares L, Danbolt NC, Gimenez C, Storm-Mathisen J (1995) Glycine transporters are differentially expressed among CNS cells. J Neurosci 15:3952-3969.

Zampighi GA, Kreman M, Boorer KJ, Loo DD, Bezanilla F, Chandy G, Hall JE, Wright EM (1995) A method for determining the unitary functional capacity of cloned channels and transporters expressed in Xenopus laevis oocytes. J Membr Biol 148:65-78. 